\title{
We have everything to succeed, but we fail to prevent residual neuromuscular blockade.
}

\author{
Bonofiglio F.C.', Domenech G. ${ }^{1}$, Kampel M.A. ${ }^{1}$, Terrasa S.A. ${ }^{2}$, Mc Loughlin S. ${ }^{1}$ \\ Hospital Italiano de Buenos Aires, 'Dept of Anesthesiology, ${ }^{2}$ Department of Research. \\ Ciudad Autónoma de Buenos Aires, Argentina.
}

BACKGROUND: Despite its morbidity, the risk of residual neuromuscular blockade (RNB) during the perioperative period is still underestimated.

OBJECTIVE: The aim of this study was to determine the incidence and risk factors for RNB.

DESIGN: Retrospective analysis.

SETTING: The study was conducted at a university teaching hospital.

PATIENTS: A sample of 240 consecutive patients that received non-depolarizing neuromuscular blocking agents (NMBAs) for general anaesthesia from June to December 2015.

OUTCOME MEASUREMENTS: Incidence and risk factors for RNB, defined as a train-of-four ratio (TOFr) < 0.9 at arrival at the Postanesthesia Care Unit (PACU).

RESULTS: Total RNB incidence was 24\% (58/240). From the group with intraoperative neuromuscular monitoring, only one patient out of 63 presented RNB when compared with 57 in a group of 177 that was not monitored, i.e. $2 \%$ vs. 31\%, respectively; $p<0.001$. Intraoperative reversal agents were used in $81 \%$ (51/63) of the monitored patients as compared with 13\% (24/177) in the non-monitored group. Regarding the use itself of reversal agents, RNB was present in $25 \%$ of the non-monitored patients, while no patient in the monitored group developed It (6/24 vs. $0 / 51$, respectively; $p=0.003)$; so the failure ratio for the non-monitored group was $40 \%(2 / 5)$ in the case of neostigmine and of $21 \%(4 / 19)$ in the case of sugammadex. In the monitored group $82 \%(42 / 51)$ of patients were reversed with sugammadex and $18 \%$ (9/51) with neostigmine.

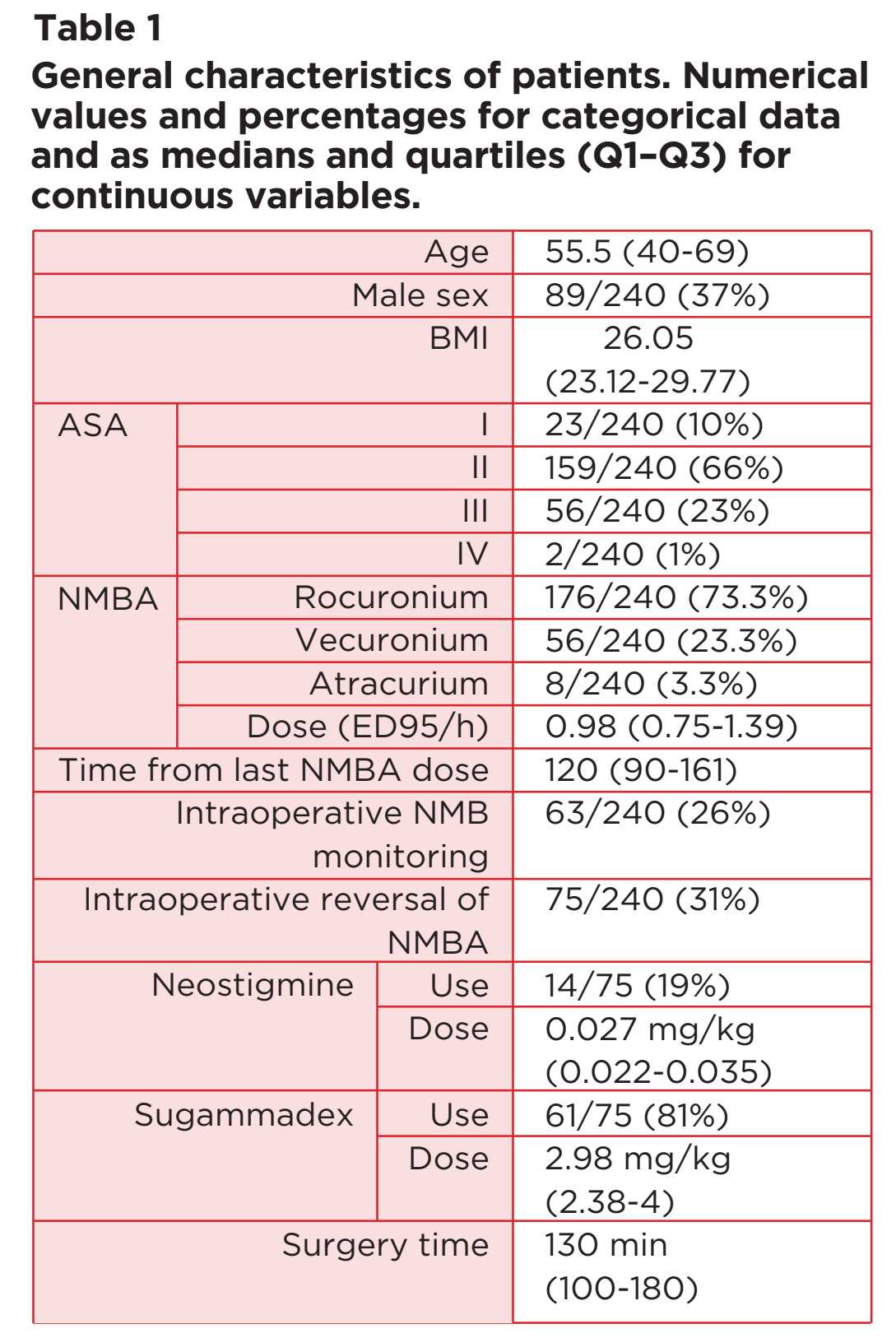

NMBA: neuromuscular blocking agent; BMI: Body Mass Index; ASA: American Society of Anesthesiologists.

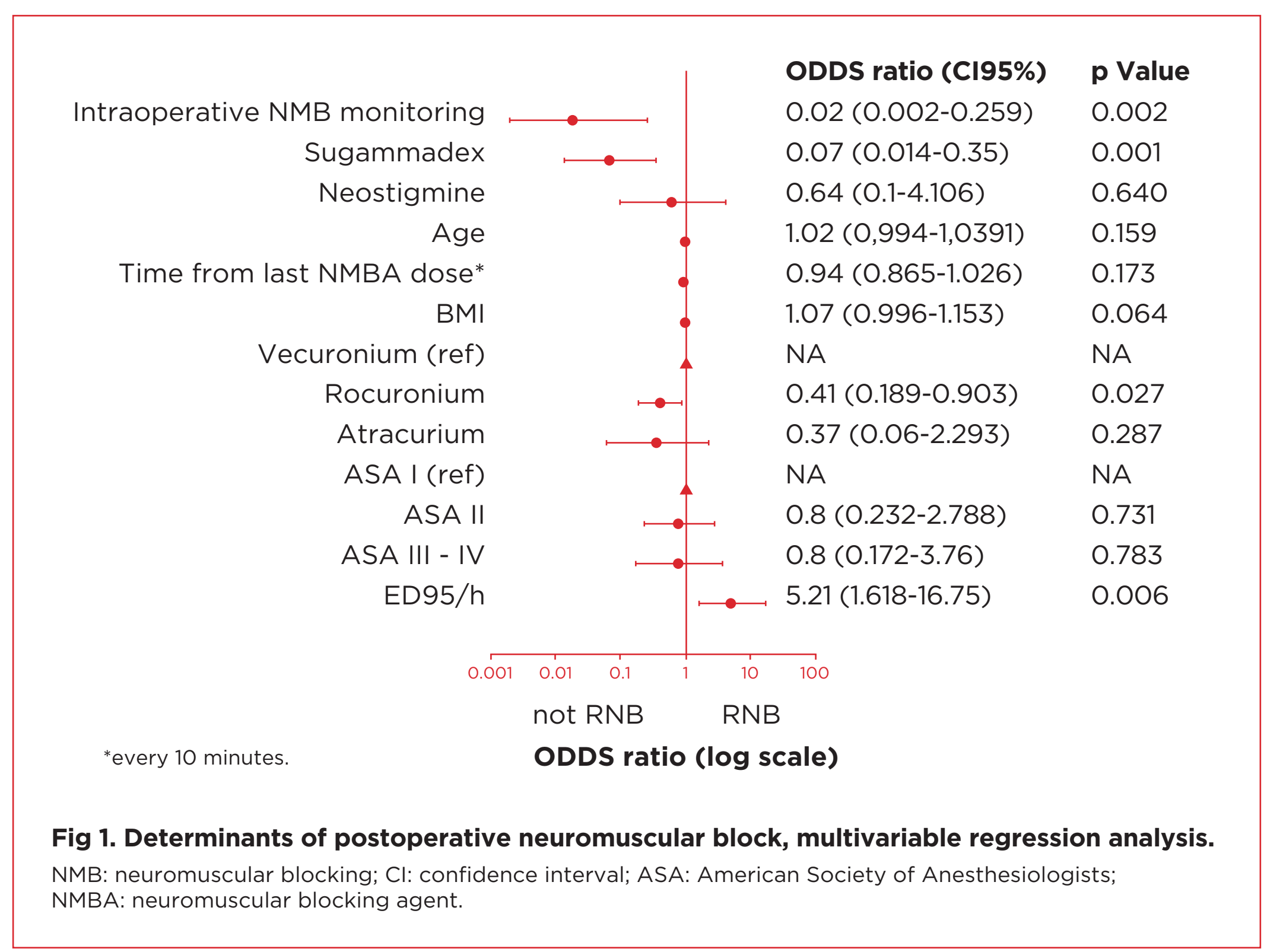

CONCLUSIONS: Intraoperative neuromuscular monitoring plays a key role in prevention followed by rocuronium and sugammadex use. Total dose of blocking agent is a strong predictor for RNB risk.

\section{References:}

1. Murphy GS, Brull SJ. Residual neuromuscular block: lessons learned. Part 1: definitions, incidence and adverse physiologic effects of residual neuromuscular block. Anesth Analg 2010; 111: 120-8.

2. Brull SJ, Murphy GS. Residual neuromuscular blockade: lessons unlearned. Part 2: Methods to reduce the risk of residual. weakness. Anesth Analg 2011; 111: 129-40 3. Baillard C, Clec'h C, Catineau J, Salhi F, Gehan G, Cupa M, Samama CM. Postoperative residual neuromuscular block: a survey of management. Br J Anaesth. 2005 Nov;95(5):622-6.

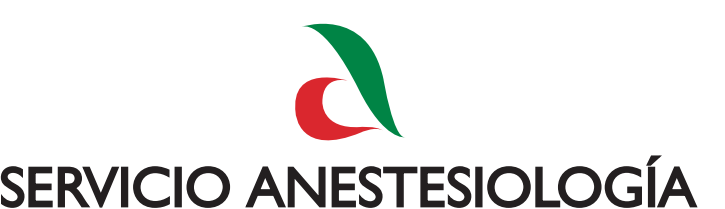

Hospital Italiano de Buenos Aires 